Adam D. Reich, Hidden Trutb: Young Men Navigating Lives In and Out of Juvenile Prison (Berkeley: University of California Press, 2010).

Adam Reich's Hidden Truth is a unique mixture. On the one hand, it is a memoir of the time Reich spent between 2001 and 2006 as a visiting teacher and in other positions at the Rhode Island Training School (RITS), a correctional institution for young offenders. During his time there, Reich-initially a Brown University undergraduate and, later, an AmeriCorps volunteer affiliated with the Broad Street Studio, a non-profit arts agency-ran writing workshops and helped organize the publication of Hidden TREWTH, a magazine written by institution residents. On the other hand, the book is also a sociological analysis of the culture of young offenders and of the institution. This element is constructed from interviews with inmates, teachers, and administrators. A doctoral student at the University of California, Berkeley, at the time of the book's publication, Reich interprets these accounts with a modern sociological perspective. The resulting book analyzes contemporary young offenders through the lenses of sociological theory and, in particular, masculinity.

Reich conceptualizes his analysis in terms of two competing models of masculinity. He characterizes both as games in which young people seek to distinguish themselves. In the first, which he calls the Game of Outlaw, young men struggle for money, power, and the respect of their peers through means such as drug dealing and violence. Since the young people at the RITS - generally working-class or poor, disproportionately African American or Latino-have limited access to conventional sources of authority such as high-paying jobs, they often instead use crime to achieve status, or what Reich calls "outsider masculinity" (25). For them, crime is an element of a cultural world in which loyalty to one's friends, obtaining money through illegal means, and the ability to inflict harm on others all provide power and respect. In the second, which Reich calls the Game of Law, young men struggle to gain status within the RITS. At the institution, they could gain status—or "insider masculinity" (25)—by accumulating points for good behavior and earning greater levels of institutional privileges.

For the young people involved, both games seem to represent a dead end. Playing the Game of Outlaw got the young people involved confined to the RITS in the first place. Even the ability to critique the Game of Outlaw in their interviews did not stop young people from playing it. Playing the Game of Law rarely gained young people much either. The institution itself had an incoherent vision of how to reform young people, so youths who sought to cooperate with it mainly just embraced its rules and discipline. Because the Game of Law was based on the controlled conditions at the RITS, young people who were released struggled to maintain this discipline without the structure that the institution provided.

As an alternative to both games, Reich favors what he terms "critical 
practice" (22) by young people in which they use arts and writing to critique social conditions. He argues that critical practice can help transcend both games, resulting in less investment in constructed gender roles. In so doing, he suggests that art and scholarship should have an activist orientation and can achieve realworld changes. As a successful example of critical practice, he cites Harmony, a young woman who was released from the RITS and returned as a teacher. Anthony, the most frequently discussed example in the book, also represents critical practice, contributing insightful material to Hidden TREWTH and working for the Broad Street Studio upon his release. Yet at least implicitly, Anthony also represents the limitations of critical practice: he fled Rhode Island after becoming a suspect in a burglary of the Broad Street Studio and a murder. This book is thought provoking, but not entirely successful. Reich's analysis is most compelling when he focuses on the Game of Outlaw and how young people use the game to achieve their visions of masculinity, even though some are aware of the artificiality of the exercise. The analysis is somewhat less compelling when dealing with the Game of Law. Reich is not entirely clear on whether the Game of Law is a means of fitting into society generally or merely an adaptation to the artificial circumstances of the RITS. In addition, Reich's advocacy of an activist role for art and scholarship might be off-putting for readers who do not share this view. These reservations aside, Hidden Truth is still a compelling read and a compelling analysis of why young people involved with crime do what they do.

David B. Wolcott

Newtown, PA

\section{Peter D. Norton, Figbting Traffic: The Dawn of the Motor Age in the American City (Cambridge: MIT Press, 2008).}

If I walk across the middle of a busy city street, there is a good chance that a car will hit me. And chances are that motorists will call me a jaywalker, or something worse. Onlookers might question why I risked my life by refusing to cross at a nearby pedestrian crosswalk. City streets, after all, belong to motorized vehicles, not other uses. Fighting Traffic: The Dawn of the Motor Age in the American City uncovers the emergence of this dominant conception of the street over eight decades ago.

Fighting Traffic examines the ways in which automobile interests, known as "motordom," reconceptualized the American city street as a car thoroughfare and delegitimated other uses that had enjoyed customary rights. The shift was not inevitable; rather, it was a "violent revolution" (2) that reached its height in the 1920s. Norton employs a social constructivist framework to study the city 